\title{
Mortality pattern of silicotic subjects in the Latium region, Italy
}

\author{
F FORASTIERE, ' SUSANNA LAGORIO,' PAOLA MICHELOZZI,' C A PERUCCI,' \\ O AXELSON ${ }^{2}$ \\ From the Epidemiologic Unit, ${ }^{1}$ Latium Regional Health Authority, 00198 Roma, Italy, and Department of \\ Occupational Medicine, ${ }^{2}$ University Hospital S-581 85 Linkoping, Sweden
}

ABSTRACT A mortality study was carried out on 595 workers who were compensated for silicosis in the Latium region, Italy, during the period 1946-84 who died between 1 January 1969 and 31 December 1984. Respiratory disorders, tuberculosis, lung cancer, bone cancer, and cirrhosis of the liver showed significantly increased risk ratios $(4 \cdot 1,3 \cdot 7,1 \cdot 5,4 \cdot 1$, and 1.9 respectively); excesses of brain cancer and leukaemia did not reach statistical significance. Lung cancer mortality was further analysed by age, period of compensation, final degree of disability, and occupational activity. The possible confounding role of smoking was assessed by comparing the lifetime smoking habits of a sample of silicotic subjects with those of the general male population as estimated by a national health survey; the prevalence of ever smokers among silicotic subjects $(70.7 \%)$ was similar to that estimated for the general population (68.5\%). The present study indicates that silicosis is associated with lung cancer even though it does not clarify the respective roles of exposure to silica and silicosis.

Experimental studies have suggested that silica induces cancer in animals, ${ }^{1-4}$ and epidemiological studies on subjects exposed to silica ${ }^{5-10}$ and workers compensated for silicosis ${ }^{11-15}$ seem to indicate the aetiological role of silica in the induction of human lung cancer. The International Agency for Research on Cancer (IARC) has recently concluded that the evidence on cancerogenicity of crystalline silica to experimental animals was "sufficient" whereas the evidence of cancerogenicity to man was "limited."16 Doubts remain about exposure to silica dust as a human carcinogen because of the lack of detailed data on past exposures and the possible confounding effect of concomitant exposure to other pulmonary carcinogens. ${ }^{17} 18$

We have studied workers compensated for silicosis in the Latium region (Italy). In this area (with $5 \mathrm{~m}$ inhabitants) exposure to silica has occurred in the past mainly because of tunnel and other construction works, quarrying, and employment in the ceramics industry.

Accepted 6 February 1989

\section{Materials and methods}

The Italian Institute for Insurance of Occupational Diseases (INAIL) is in charge of the disability compensation of occupational diseases. A compensation claim for silicosis is reviewed with regard to (i) radiographic findings consistent with pneumoconiosis; (ii) verified history of occupational exposure to silica dust; and (iii) degree of disability exceeding $10 \%$ (or $20 \%$ before 1981 ).

A complete list of people with compensated silicosis was not available because of changes in the recording system and periodic removal of old cases. Therefore, INAIL provided a list of male workers in the Latium region who had received a disability pension for silicosis during the period 1946-84 and whose award had been discontinued because of death or other reasons. For each subject the following information was available: personal data, date on which silicosis was first noted, date of initial compensation, degree of disability, and last occupation entailing exposure to silica. When relevant information on dates and occupation was missing in the original file, it was retrieved through the provincial offices of INAIL.

Altogether 952 men were enrolled in the study and their vital status was ascertained for the period 
1 January 1969-31 December 1984 through the registry offices of the municipality of residence. The causes of death were retrieved either by $(a)$ record linkage with national mortality or $(b)$ direct retrieval through the registry offices. Details of the former procedure are given elsewhere. ${ }^{19}$ Briefly, we linked records of subjects known to have died with an anonymous national mortality file released by the Central Bureau of Statistics (ISTAT), according to the following keys: sex, date of birth, date of death, civil status, province of residence, and place of death. Out of 325 deaths forming the subset occurring in 1969-79 (the period of the ISTAT file), a match was obtained for 252 $(77.5 \%)$, so that the ICD codes assigned by the ISTAT could be used for the analysis. For subjects with unsuccessful record linkage or who died after 31 December 1979, the underlying cause of death was coded by an expert nosologist according to the 8th ICD revision.

The number of subjects who had died was 607 and cause of death was known for 595. The mortality experience of the regional male population, by age and cause, was made available by ISTAT for 1969-79. ${ }^{20}$ Owing to the lack of information on the underlying population at risk, a mortality odds ratio (MOR) approach was adopted for the analysis. ${ }^{21-23}$ Several case series were defined as deaths from particular causes of interest among silicotic subjects and the general population of Latium respectively. The corresponding referent series, auxiliary deaths (193 deaths from the silicotic subjects and 79245 from the general population), included all other causes except those deaths that could be positively related to silicosis (tuberculosis, lung cancer, respiratory diseases) or that could have been selectively undercertified among such a group (cardiovascular diseases) ${ }^{22}$ This means that, in each specific calculation, the cause of death considered in any of the case series was removed from the referents. The mortality odds ratios were calculated after stratification on age $(40-54,55-64,65-74, \geqslant 75)$ and calendar period $(1969-73,1974-78,1979-84)$ with a standardisation to the age-time distribution of the study population. ${ }^{23}$ The $95 \%$ confidence intervals $(95 \% \mathrm{CI})$ were estimated assuming a Poisson distribution of the observed cases.

For estimating the possible confounding role of smoking, a random sample of 249 subjects was drawn from the INAIL main file of compensated silicotics in the region, irrespective of vital status and cause of death. Smoking habits were retrieved from the personal files at the provincial offices of INAIL. Reference figures for smoking among Italian men were available from a national interview survey carried out in 1983. ${ }^{24}$ The prevalence of ever-smokers in the sample of silicotic subjects was compared with that of the general population, with adjustment to the age distribution of the silicotic subjects at the time of application for compensation.

\section{Results}

CAUSE SPECIFIC MORTALITY

The mortality odds ratio (table 1) was raised for: respiratory disorders $(4 \cdot 1)$ due particularly to the excess mortality from silicosis (105 deaths). Death from tuberculosis were also higher than expecteff $(M O R=3.7)$. The overall cancer mortality was not. increased but excess risks were evident for lung cance $(M O R=1 \cdot 5)$ and bone cancer $(M O R=4 \cdot 1)$. Finally? deaths from liver cirrhosis were greater than expected $(\mathrm{MOR}=1.9)$, whereas mortality from circulatory diseases $(\mathrm{MOR}=0.81)$ was lower than expected.

\section{LUNG CANCER}

A total of 64 lung cancer deaths were recorded ancid table 2 shows lung cancer mortality by age, period of initial compensation, degree of disability, and? occupational activities. The mortality odds ratio waș particularly increased below age 65 . No excess waš present among those compensated in the earliest period (1946-65), whereas a significant increase was seen for more recently compensated subjects. The risk of lung cancer did not vary across the categories of final severity of disability. Not all occupations held byo the silicotic subjects had an excess risk for lung cancer? A significant excess was present for mining and potteryd industries.

Table 1 Subjects compensated for silicosis in the Latium 응 region (1946-84). Observed deaths, mortality odds ratios (MOR) and $95 \%$ confidence intervals $(95 \% \mathrm{CI})$ for selec causes of death. ICD Codes (8th rev)

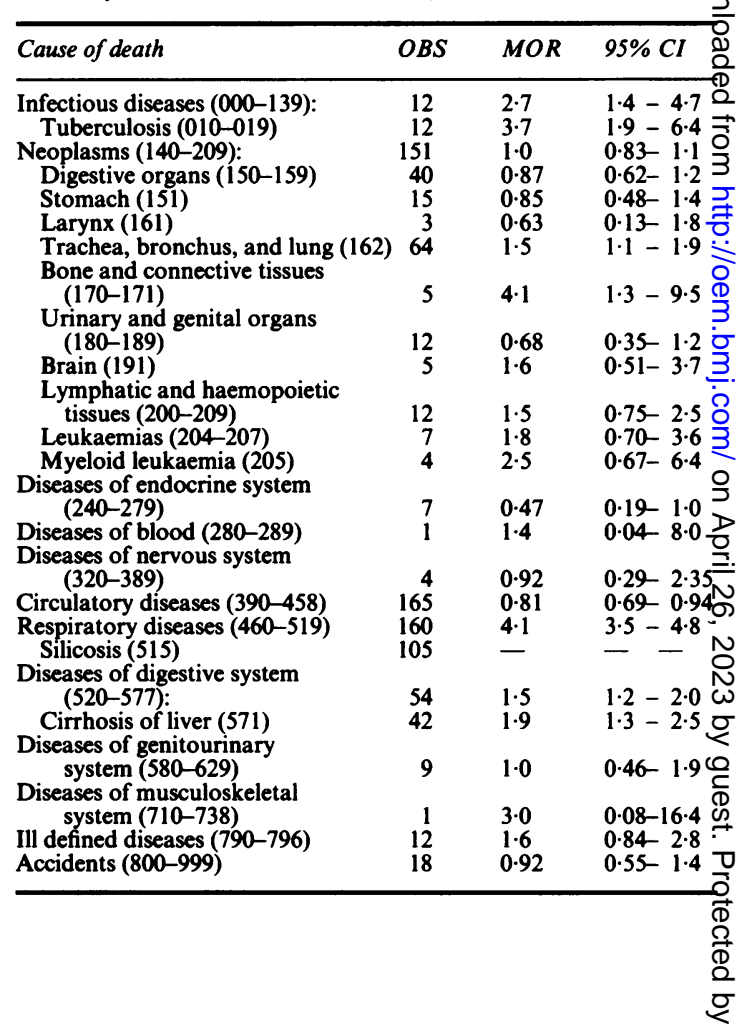


Table 2 Lung cancer observed deaths (OBS), mortality odds ratios (MOR), and $95 \%$ confidence intervals (95\% CI) by selected characteristics

\begin{tabular}{|c|c|c|c|}
\hline & $O B S$ & $M O R$ & $95 \% \mathrm{CI}$ \\
\hline $\begin{array}{l}\text { Age at death: } \\
\quad \begin{array}{l}40-64 \\
\geqslant 65\end{array}\end{array}$ & $\begin{array}{l}40 \\
24\end{array}$ & $\begin{array}{l}1.9 \\
1 \cdot 1\end{array}$ & $\begin{array}{l}1.4-2.6 \\
0.58-1.6\end{array}$ \\
\hline $\begin{array}{l}\text { Period of initial compensati } \\
1946-65 \\
1966-75 \\
1976-84\end{array}$ & $\begin{array}{r}7 \\
38 \\
19\end{array}$ & $\begin{array}{l}0 \cdot 60 \\
1 \cdot 7 \\
2 \cdot 0\end{array}$ & $\begin{array}{l}0 \cdot 24-1 \cdot 2 \\
1 \cdot 2-2 \cdot 3 \\
1 \cdot 2-3 \cdot 1\end{array}$ \\
\hline $\begin{array}{l}\text { Degree of disability at death } \\
<26 \\
26-50 \\
51-75 \\
>75\end{array}$ & $\begin{array}{r}6 \\
27 \\
15 \\
16\end{array}$ & $\begin{array}{l}1 \cdot 7 \\
1 \cdot 3 \\
1 \cdot 4 \\
1 \cdot 8\end{array}$ & $\begin{array}{l}0.63-3 \cdot 7 \\
0 \cdot 88-1 \cdot 9 \\
0 \cdot 78-2 \cdot 3 \\
1 \cdot 01-2 \cdot 9\end{array}$ \\
\hline $\begin{array}{l}\text { Occupational activities: } \\
\text { Mining } \\
\text { Quarrying, stone cutting } \\
\text { Construction, tunnelling } \\
\text { Metal workers } \\
\text { Bricklaying } \\
\text { Pottery } \\
\text { Other }\end{array}$ & $\begin{array}{r}10 \\
6 \\
23 \\
3 \\
4 \\
17 \\
1\end{array}$ & $\begin{array}{l}2.5 \\
1.1 \\
1.4 \\
1.6 \\
0.89 \\
2 \cdot 1 \\
0.76\end{array}$ & $\begin{array}{l}1.2-4.6 \\
0.42-2.5 \\
0.86-2.0 \\
0.32-4.6 \\
0.24-2.3 \\
1.2-3.3 \\
0.02-4.2\end{array}$ \\
\hline
\end{tabular}

Information on smoking habits was available for 48 cases of lung cancer $(75 \%)$ and 157 subjects from the sample of silicotics $(63 \%)$. The prevalence of eversmokers was $\mathbf{8 7 . 8 \%}$ among the cases of lung cancer (five non-smokers) and 70.7\% (95\% CI $=63 \cdot 6-77 \cdot 8)$ in the silicotic population, the latter figure being in good agreement with an age adjusted prevalence of smokers in the general population of $68 \cdot 5 \%$.

\section{Discussion}

The present study shows an excess risk for respiratory deaths, including tuberculosis, among subjects receiving compensation for silicosis. The occurrence of lung cancer is significantly increased mainly because of an excess in the subgroup aged under 65 . Certification of cause of death in men of this age should be of high quality. The excess of respiratory cancer supports the evidence from previous studies of a raised risk of lung cancer among workers exposed to silica, especially in silicotic patients.

The interpretation of the relative risks found in different subgroups of the study population is not straightforward owing to the small number of subjects in some of the subgroups of interest. The deficit of lung cancer mortality among those compensated in the earliest calendar period could reflect a higher mortality from a more severe form of silicosis, as a "competing risk." On the other hand, there is no variation in the risk of lung cancer according to the degree of disability.

The risk of lung cancer seems to differ among silicotic subjects from different occupational groups, even if some estimates are clearly unstable owing to small numbers. Exposure to other occupational carcinogens could act as confounders of the relation. ${ }^{18}$
For instance, miners have been exposed especially to radon daughters, and construction workers and foundry workers may have been exposed to asbestos and to polycyclic aromatic hydrocarbons, respectively. The excess risk among ceramic workers, on the other hand, which is consistent with findings from a previous study, ${ }^{6}$ relates to a work environment where silica is the predominant risk factor for respiratory cancer. Exposure to non-fibrous talc, which Thomas and Stewart reported as a risk factor for lung cancer among pottery workers, ${ }^{10}$ would hardly be a strong enough confounder to explain the association. ${ }^{25}$

There are several reasons why studies based on silicotic subjects receiving compensation may be biased towards a silicosis-lung cancer association. ${ }^{16} \mathrm{~A}$ diagnosis of lung cancer, for instance, could affect the recognition of a silicotic disease, thus artificially increasing the risk of lung cancer among those receiving compensation. Excluding deaths occurring within three years of compensation, however, 50 cases of lung cancer and 146 referents remain and the excess risk for lung cancer is unchanged (MOR $=1.5 ; 95 \%$ $\mathrm{CI}=1 \cdot 1-2 \cdot 1)$.

Certification of death among silicotic subjects may be focused on chest problems and necropsy rates could be higher than in the general population. We had access to the individual medical files for 42 cases of lung cancer whose death occurred in hospital. A necropsy had been performed in four subjects and did not alter the premortem diagnosis of lung cancer. Of the 22 remaining cases out of the 64 total, 15 died at home and are unlikely to have been necropsied, given the local rules. Therefore, the excess risk of lung cancer found in this study does not seem to be due to information bias from a greater frequency of necropsy.

The regulations for compensating silicosis vary between countries, so comparison is difficult. The relative risk for lung cancer that we observed, $1 \cdot 5$, is lower than those estimated among silicotic subjects in Canada, 1.98, ${ }^{11}$ and in Finland, 3.05. ${ }^{12}$

Smoking habits represent a potential confounder in this study. The estimate of $70.7 \%$ ever smokers among silicotic subjects is close to the expected prevalence of $68.5 \%$ calculated from a national survey. ${ }^{24}$ In the past the proportion of smokers in Italy was higher, ${ }^{26}$ so the smoking habits of the silicotic subjects are compatible with those of the general population, thus any confounding effect would be small. ${ }^{27}$

It has been suggested that exposure to silica may be associated with disorders of the genitourinary system, ${ }^{28}$ malignant neoplasms of the lymphohaemopoietic system, including leukaemia, both in animals ${ }^{4}$ and in man, ${ }^{29}$ bone cancer,' gastrointestinal tract cancer, ${ }^{7}$ and also diseases of connective tissue, such as rheumatoid arthritis. ${ }^{30}$ An excess of bone cancer and an increased risk of myeloid leukaemia, as found in the present study, has also been reported among United States granite workers ${ }^{9}$ and gold 
miners. ${ }^{29}$ The five cases of bone cancer and the four cases of myeloid leukaemia in our study did not cluster in any particular occupation, therefore rendering, in the absence of any other obvious explanation, an association with silicosis more likely than one with exposure to silica.

The excesses from the above mentioned cancers are balanced by a deficit in other tumour sites, mainly those of the digestive tract. This is in contrast with the findings from Finland ${ }^{7}$ but chance alone could explain such a result.

A traditional cohort approach was not feasible because some records of compensated silicotic patients in our region were missing. It is unlikely, however, that there was any systemic loss with regard to cause of death. Furthermore, we have adopted a mortality odds ratio approach to avoid the pitfalls of proportional mortality analysis ${ }^{31} 32$ by selecting denominator deaths not influenced by the exposure of interest.

The results of the present study indicate that silicosis is associated with lung cancer, as has been already suggested, but the role of exposure to silica or of the silicotic disease in the induction of lung cancer remains unclear. Other conditions were associated with silicosis in this study, especially bone cancer and myeloid leukaemia.

\section{References}

1 Dagle GE, Wehener AP, Cleark ML, Buschbom RL. Chronic inhalation exposure of rats to quartz. In: Goldsmith DF, Winn DM, Shy CM, eds. Silica silicosis, and cancer: controversy in occupational medicine. New York: Praeger, 1986:225-6. (Cancer research monographs, vol 2.)

2 Groth DH, Stettler LE, Platek SF, Lal JB, Burg JR. Lung tumors in rats treated with quartz by intratracheal instillation. In: Goldsmith DF, Winn DM, Shy CM, eds. Silica silicosis, and cancer: controversy in occupational medicine. New York: Praeger, 1986:243-4. (Cancer research monographs, vol 2.)

3 Holland LM, Wilson JS, Tillery MI, Smith DM. Lung cancer in rats exposed to fibrogenic dusts. In: Goldsmith DF, Winn DM, Shy CM, eds. Silica silicosis, and cancer: controversy in occupational medicine. New York: Praeger, 1986:267-80. (Cancer research monographs, vol 2.)

4 Wagner MMF, Wagner JC, Griffiths DM. Silica-induced malignant histiocytic lymphoma. Incidence linked with strain and type of silica. Br J Cancer 1980;42:908-17.

5 Fletcher AC. The mortality of foundry workers in the United Kingdom. In: Goldsmith DF, Winn DM, Shy CM, eds. Silica silicosis, and cancer: controversy in occupational medicine. New York: Praeger, 1986:385-402. (Cancer research monographs, vol 2.)

6 Forastiere F, Lagorio S, Michelozzi P, et al. Silica, silicosis and lung cancer among ceramic workers: a case referent study. Am J Ind Med 1986;10:363-70.

7 Koskela R-S, Klockars M, Jarvinen E, Kolari PJ, Rossi A. Mortality and disability among granite workers. Scand $J$ Work Environ Health 1987;13:18-25.

8 Koskela R-S, Klockars M, Jarvinen E, Kolari PJ, Rossi A. Cancer mortality of granite workers. Scand J Work Environ Health 1987;13:26-31.

9 Steenland K, Beaumont J. A proportionate mortality study of granite cutters. Am J Ind Med 1986;9:189-201.

10 Thomas TL, Stewart PA. Mortality from lung cancer and respiratory disease among pottery workers exposed to silica and talc. Am J Epidemiol 1987;125:35-43.

11 Finkelstein M, Kusiak R, Suranyi G. Mortality among miners receiving workmen's compensation for silicosis in Ontario 1940-1975. J Occup Med 1982;24:663-7.

12 Kurppa K, Gudbergsson H, Hannunkari I, et al. Lung cancet among silicotics in Finland. In: Goldsmith DF, Winn DM, Sh CM, eds. Silica silicosis, and cancer: controversy in occupationat medicine. New York: Praeger, 1986:311-20. (Cancer researcie monographs, vol 2.)

13 Westerholm P, Ahlmark A, Maasing R, Segelberg I. Silicosis and lung cancer: a cohort study. In: Goldsmith DF, Winn DM, Sh: CM, eds. Silica silicosis, and cancer: controversy in occupationa medicine. New York: Praeger, 1986:327-33. (Cancer research है monographs, vol 2.)

14 Westerholm P. Silicosis: observations on a case register. Scand $\vec{D}$ Work Environ Health 1980;6suppl 2:1-86.

15 Zambon P, Simonato L, Mastrangelo G, Winkemann R, Saia $B_{\mathfrak{\omega}} \vec{~}$ Crepet M. Mortality of workers compensated for silicosis during the period 1959-1963 in the Veneto region of Italy. Scan\& $J$ Work Environ Health 1987;7:175-82.

16 International Agency for Research on Cancer. Monographs on the evaluation of the carcinogenic risk of chemicals to humans. Vobr 42. Silica and some silicates. Lyon: IARC, 1987.

17 Goldsmith DF, Guidotti TL, Johnston DR. Does occupationa exposure to silica cause lung cancer? Am J Ind Med 1982;3 423-40.

18 Heppleston AG. Silica, pneumoconiosis and carcinoma of the lung. Am J Ind Med 1985;7:285-94.

19 Lagorio S, Forastiere F, Perucci CA, Altavista P, Costa G, Vigotti MA. Cause of death ascertainment in follow-up studiess comparison of procedures available in Italy. Epidemiologia \& Prevenzione 1987;31:57-61.

20 Adorante E, Angeli A, Capocaccia B. Modalita' d'uso e struttura d un archivio di dati ISTAT di mortalita'. Rapporto ISTISAN튼 Rome: Istituto Superiore di Sanita', 1981.

21 Miettinen OS, Wang J-D. An alternative to the proportiogat mortality ratio. Am J Epidemiol 1981;114:144-8.

22 Wang J-D, Miettinen OS. Occupational mortality studfesं Principles of validity. Scand J Work Environ Health 19880 153-8.

23 Spiegelman D, Wang J-D, Wegman D. Interactive electroni computing of the mortality odds ratio. Am J Epidemiol 1983ब 188:599-607.

24 Central Bureau of Statistics (ISTAT). Indagine statistica sull condizioni di salute della popolazione e sul ricorso ai serviz sanitari (Novembre 1983). (Note e relazioni No 1.) Romes Istituto Centrale di Statistica, 1986.

25 Lagorio S, Forastiere F, Michelozzi P, Cavariani F, Perucci CA Axelson $\mathrm{O}$. A case-referent study on lung cancer among cerami?. workers. Lyon: International Agency for Research on Cancers (in press).

26 La Vecchia C. Smoking in Italy 1949-1983. Prev Med 1986;15: 274-81.

27 Axelson O. Aspects on confounding in occupational health. epidemiology. Scand J Work Environ Health 1978;4:85-9.

28 Thun M, Stayner L, Brown D, Waxweiler R. Mining and deaths from chronic renal failure. Lancet 1982;ii:606.

29 Brown DP, Kaplan SD, Zumwalde RD, Kaplowitz M, Archer VEO Retrospective cohort mortality study of underground gold mine workers. In: Goldsmith DF, Winn DM, Shy CM, eds. Silic silicosis, and cancer: controversy in occupational medicine. New. York: Praeger, 1986:335-50. (Cancer research monographs, vol 2.)

30 Klockars M, Koskela R-S, Jarvinen E, Kolari PJ, Rossi A. Silicæn exposure and rheumatoid arthritis: a follow up study of granit? workers 1940-81. Br Med J 1987;294:997-1000.

31 Decoufle P, Thomas TL, Pickle LW. Comparison of the propore tionate mortality ratio and standardized mortality ratio ris measures. Am J Epidemiol 1980;111:263-9.

32 Kupper LL, McMichael AJ, Symons MJ, Most BM. On the utilit of the proportionate mortality analysis. J Chronic Dis 1978; 31:15-22. 